\title{
La democracia en el filo de la navaja: límites y posibilidades para la implementación de una agenda de reforma urbana en Brasil ${ }^{*}$
}

\author{
RAQUEL ROLNIK** \\ ** Facultad de Arquitectura de la Universidad de Sáo Paulo USP. Relatora Especial para el derecho a la vivienda \\ adecuada del Consejo de Derechos Humanos de las Naciones Unidas
}

\begin{abstract}
In Brazil the 1990s constituted years of institutional achievements in the fields of housing and urban rights, given the incorporation of the principles of the social function of cities and property, the recognition of tenure rights for slum dwellers and the direct participation of citizens in the decision making process of urban policies, within the 1988 Constitution. These proposals have become the pillars of the Urban Reform agenda which has penetrated the federal government apparatus since the creation of the Ministry of Cities under Lula's administration. The article evaluates the limits and possibilities for the implementation of this agenda through the analysis of two policies proposed by the Ministry: the National Council of Cities and the campaign for Participatory Master Plans. The approach is based on the organization of the Brazilian State in terms of urban development, the relationship with the political system and the characteristics of Brazilian democracy.
\end{abstract}

KEYWORDS: participatory planning, urban policy, democracy

RESUMEN Los años '90 representaron en Brasil avances institucionales en el campo del Derecho a la Vivienda y el Derecho a la Ciudad; en el reconocimiento de los derechos de millones de habitantes de los asentamientos urbanos informales y en la participación directa de estos ciudadanos en los procesos de toma de decisiones sobre la política urbana. Estas propuestas constituyen los pilares de la Agenda de Reforma Urbana, que a partir de la creación del Ministerio de las Ciudades durante el gobierno de Lula, ingresa en el ámbito del Poder Ejecutivo federal. El artículo evalúa los límites y las posibilidades de implementación de esta agenda a través de la trayectoria de dos políticas propuestas por el Ministerio: el Consejo Nacional de las Ciudades y la Campaña por los Planes Directores Participativos; centrando su análisis en la organización del Estado en el área de desarrollo urbano en su relación con el sistema político y las características de la democracia brasileña.

PALABRAS CLAVE: planificación participativa, política urbana, democracia

\footnotetext{
Este artículo fue escrito inmediatamente después de mi experiencia como Secretaria Nacional de Programas Urbanos del Ministerio de las Ciudades durante el primer mandato del presidente Lula (2003-2007). Agradezco a los profesores Pedro Luiz Barros e Silva, Marcus André Melo, Eduardo Marques, Marta Arretche y Doraci Lopes por las indicaciones bibliográficas que hicieron posible para una urbanista una incursión en la ciencia política. Las interpretaciones y utilizaciones de estas referencias son responsabilidad exclusiva de la autora.
}

Recibido el 25 de septiembre de 2008, aprobado el 10 de marzo de 2009.

Correspondencia: Raquel Rolnik, FAU Cidade Universitária Rua do Lago 876, CEP 05508.080, São Paulo SP

Brasil. E-mail: raquelrolnik@usp.br 


\section{Introducción}

Los años 90 representaron para Brasil un período de intenso debate acerca del papel de los ciudadanos y sus organizaciones en la gestión de las ciudades, tanto en el seno de la sociedad civil como en los partidos políticos y en el gobierno. Por otro lado, estos años se caracterizaron por presentar avances institucionales en el campo del Derecho a la Vivienda y a la Ciudad, ya que se incorporó en 1988 en la nueva Constitución Nacional un capítulo de política urbana estructurado en torno a la noción de la función social de la ciudad y de la propiedad y del reconocimiento de los derechos de los millones de habitantes de los asentamientos informales urbanos del país. También se incorporaron instrumentos de participación directa de los ciudadanos en los procesos de toma de decisión sobre esta política. Estos fueron -a partir del período de la nueva constitución- los puntos centrales de la llamada agenda de reforma urbana, cuyos protagonistas han sido los movimientos populares, organizaciones no gubernamentales, sindicatos e instituciones académicas y de investigación que se asociaron en la defensa de la gestión democrática y de la promoción del derecho a la ciudad (Santos Jr., 2007, p. 297).

La década del noventa también trajo consigo los efectos de las reformas macroeconómicas de carácter liberal iniciadas a principio de los años 90 en las ciudades brasileñas, y, especialmente, en las metrópolis. Estas reformas impactaron la economía de las ciudades generando desempleo y radicalizando las asimetrías económicas y sociales ya existentes; así como sobre la capacidad de los gobiernos y actores sociales de enfrentarlas. A su vez, vinieron acompañadas de una agenda de reforma del Estado con eje en la privatización de políticas públicas, en propuestas de modernización y reducción del Estado, acompañadas de un discurso participacionista y de revalorización de la sociedad civil redefinida como tercer sector (Dagnino, Olvera y Panfichi, 2006; Telles, 2007; Ribeiro, 2004; Santos Jr. y Ribeiro, 2003).

Por último, fue también en este mismo período que se implementó progresivamente el proceso de descentralización federativa y de fortalecimiento y autonomía de los poderes locales propuestos en la Constitución de 1988, limitados tanto por las restricciones impuestas por el ajuste macroeconómico como por la alta dosis de continuidad política que tuvo el proceso de redemocratización brasileña (Avritzer, 2003; Alston, Melo, Mueller y Pereira, 2005).

A nuestro entender, la combinación particular y perversa de estos elementos, estrechamente ligada a la pesada herencia de una lógica depredadora en la gestión del territorio, concentradora y restrictiva a ciertos grupos sociales, fue la que dictó las marchas y contra-marchas de la agenda de la Reforma Urbana en el país. Si bien esta agenda no logró constituir una base con suficiente fuerza política para incidir profundamente en la dinámica estatal y en las relaciones entre la sociedad política y la sociedad civil de forma de promover la gestión de las ciudades hacia la creación de un espacio más cohesivo, incluyente y sustentable, esta sí constituyó una fuente de permanente tensión e innovación cultural introducida por los actores sociales, lo que ha ampliado desde un punto de vista territorial y político la democracia brasileña (Silva, 2004; Santos Jr., 2007).

En este artículo evaluamos los límites y posibilidades de la implementación de la agenda de la Reforma Urbana, tomando como objeto de reflexión su incorporación a la política urbana 
promovida por el Ministerio de las Ciudades en el ámbito del Gobierno de Lula. Este balance, aunque restringido apenas a algunos aspectos de dichas políticas, pretende contribuir a la reflexión sobre los desafíos de la política urbana en Brasil, desde el punto de vista de la frágil y vigorosa democracia brasileña.

\section{La agenda de la Reforma Urbana y el Ministerio de las Ciudades}

La creación del Ministerio de las Ciudades expresó el reconocimiento por parte del gobierno de la necesidad de constituir un ámbito en el gobierno federal, después de casi veinte años de institucionalidades erráticas y dispersas en distintos ministerios, un locus para la formulación e implementación de la política urbana (Santos Jr., 2004; Maricato, 2006). De 1964 a 1985, la política fue liderada por el Banco Nacional de Habitación (BNH). Luego de su desaparición, la tarea fue asumida por otro banco, la Caixa Econômica Federal, y las políticas nacionales sectoriales de habitación, saneamiento y transporte urbano pasaron a carteras de distintos ministerios.

Para los actores vinculados al movimiento social por la Reforma Urbana, la creación del Ministerio representaba la posibilidad de avanzar hacia la democratización de la gestión urbana, teniendo a ésta como uno de los pilares institucionales de su agenda, así como la posibilidad de ampliar los espacios de democracia participativa que hasta entonces se habían experimentado, sobre todo a nivel local (Avritzer, 2003; Dagnino, Olvera y Panfichi, 2006; Melo y Rezende, 2004). La respuesta a esta demanda se dio a través de la creación de un Consejo Nacional de las Ciudades, parte integrante de la estructura ministerial y órgano central en la formulación y negociación de políticas, donde tanto sectores gubernamentales (de los tres niveles de gobierno) como los sectores de la sociedad civil (sector empresarial, sindicatos, organizaciones profesionales, ONG, instituciones académicas y de investigación, y movimientos sociales) están representados. Estos integrantes son electos a través de asambleas según sectores entre los delegados presentes en las Conferencias Nacionales ${ }^{1}$. El proyecto inicial de construcción del Consejo se concibió como un ámbito de interacciones políticas, arena abierta donde la trama de intereses en torno a la política urbana tuviese una posibilidad de expresión y negociación; donde estuviesen representados con gran peso los principales demandantes de estas políticas -los sin techo, sin casa, habitantes de asentamientos precarios del país, además de todas las categorías profesionales responsables de la operación de la maquinaria estatal de varios niveles del gobierno, sectores empresariales y financieros, políticos, sindicales y de organizaciones técnico-profesionales y ONG del sector.

El Ministerio incorporó también en su estructura y en su política otro punto central de la agenda de la Reforma Urbana: las acciones e instrumentos para garantizar la función social de la ciudad y de la propiedad urbana -que la Constitución y el Estatuto de la Ciudad habían

\footnotetext{
La primera Conferencia Nacional se realizó en 2003 y contó con 2.500 delegados. A excepción de los 250 representantes del poder público federal, que fueron designados por el Poder Ejecutivo, los delegados de la Conferencia Nacional podían ser electos en las Conferencias Estaduales (75\%) o designados por organizaciones de carácter nacional (25\%). La Conferencia de 2003 fue precedida por 1.427 conferencias municipales, 185 conferencias regionales y 27 estaduales, involucrando a 3.457 municipalidades.
} 
definido como competencias locales, dependientes de la aprobación de Planes Directores por las Cámaras Municipales. El capítulo de política urbana en la nueva Constitución del 88 requería una reglamentación, lo que se logró con la aprobación del Estatuto de la Ciudad en el 2001. El Estatuto introdujo nuevos instrumentos de gestión del suelo urbano aplicables por las municipalidades para logar el cumplimento de la función social de la ciudad y de la propiedad, y para fomentar la participación ciudadana en la gestión. Estos instrumentos, para poder ser aplicados en los municipios, exigían, de acuerdo al texto constitucional y el Estatuto, la elaboración de Planes Directores en todas las ciudades de más de 20.000 habitantes. Estos planes deberían ser aprobados por las Cámaras Municipales antes de octubre del 2006. La introducción de la obligatoriedad de elaboración de los planos directores no formaba parte de las propuestas incluidas en la enmienda popular de Reforma Urbana que fue presentada al Congreso Constituyente por una coalición de movimientos sociales y sindicatos. Ésta fue incluida en el proceso de negociación de la enmienda en el Congreso mismo. Como el Plan Director se transformó en requisito para implementar instrumentos referentes a la función social de la propiedad, desde 1989, cuando coaliciones “democrático-populares” ganaron las elecciones en varias ciudades brasileñas, se inició un proceso de experimentación hacia la revisión conceptual y metodológica de la planificación urbana en la dirección de una planificación participativa que permitiese la inclusión socio-territorial de los segmentos de menores ingresos.

A partir de una propuesta elaborada por el Ministerio, el Consejo de las Ciudades decidió estructurar una campaña con el fin de fomentar la elaboración de Planes Directores Participativos en las municipalidades, ya que en Brasil esta es una competencia de los gobiernos locales. Esta campańa se dirigió a los gobiernos y a la sociedad civil en las ciudades que estaban obligadas por ley a elaborar sus Planes. El objetivo de la Campaña era difundir los nuevos contenidos así como los nuevos métodos que la planificación territorial -y en particular los Planes Directores- deberían incorporar, teniendo en cuenta la misión que se les atribuía por el nuevo marco legal: hacer explícita "la función social de cada segmento de su territorio" considerando las realidades socio-territoriales de cada municipio. Todo esto debería realizarse a través de un proceso participativo de discusión y de construcción de consensos que deberían llevarse a cabo en cada ciudad.

A partir del debate en el ámbito del Consejo Nacional de las Ciudades, y en conjunto con las organizaciones de la sociedad civil e instituciones gubernamentales integrantes del Consejo, se definió como estrategia apoyar la organización de núcleos de movilización y capacitación en cada Estado del país, articulando una red de actores en todo el territorio nacional. Esta red fue constituida por organizaciones técnicas, académicas, instituciones de investigación, el poder público estadual y municipal, movimientos sociales y populares, y, en algunos Estados, el Ministerio Público. A partir de la formación de los Núcleos de la Campaña en todos los Estados brasileños y la elaboración de material de difusión y capacitación en varios medios, la campaña se propuso sensibilizar, capacitar y monitorear los municipios obligados en cada estado. Asimismo, la campaña facilitó la asistencia técnica y recursos, en conjunto con el Ministerio, para la elaboración de los Planes Directores².

2 Además del apoyo a través de la difusión de materiales didácticos - el KIT del Plan Director- como videos, cartillas y materiales de referencia técnica y de movilización, el Ministerio invirtió en la formación de multiplicadores 
Otros puntos de la agenda de la Reforma Urbana, como el derecho a la vivienda, fueron centrales en la política del Ministerio a través de políticas de financiamiento de producción habitacional y urbanización de asentamientos precarios, de la regularización y titulación de los asentamientos, y luego de la aprobación de la ley federal de iniciativa popular, a través de la creación del Sistema Nacional de Vivienda de Interés Social, de manera de articular los subsidios provenientes de los presupuestos de varios niveles de gobierno y dirigirlos a la promoción de la Vivienda de Interés Social, a partir de criterios definidos en el ámbito de los consejos gestores electos en cada nivel federativo.

Debido a las limitaciones de espacio, el objetivo de este artículo no será analizar esta área de políticas ni las demás políticas promovidas por el Ministerio de las Ciudades en el campo del saneamiento ambiental y de movilidad urbana (Brasil MCidades, 2004). Hemos optado por focalizar aquí algunas de las propuestas de Reforma del Estado que tuvieron como eje la pluralización de los actores y la diversificación de los lugares de ejercicio de la representación en la elaboración e implementación de la política urbana (Lavalle, Houtzager y Costello, 2006).

La experiencia de construcción de políticas en el Consejo Nacional de las Ciudades, así como de los procesos de planificación territorial participativo apostaron a la construcción de espacios públicos como locus de ejercicio de la solidaridad cívica y de conquista del derecho a tener derechos de una parte significativa de brasileños que se caracterizaban por estar insertos de manera precaria en las ciudades y en las políticas urbanas. La agenda desafiaba la maquinaria pública, burocracias estatales, partidos y líderes políticos a "producir instituciones capaces de generar cambios y acuerdos entre los diferentes actores locales con respecto al futuro de su sociedad, promover redes de actores trabajando sobre los problemas públicos, instalar instrumentos de movilización de los ciudadanos, crear normas para garantizar la implementación de estos acuerdos, tener capacidad estratégica de articulación politica, y sobre todo ganar la confianza de los actores y reducir las incertidumbres del sistema politico" (T.L. de Milani, 2006, p. 232) 3 .

En esta agenda, el espacio público es tomado en su doble acepción: como campo de interacciones políticas (arena) y como expresión territorial del pacto que dichas interacciones políticas establecen. Desde el punto de vista de la política urbana, se trató de generar un pacto territorial en la ciudad, reconociendo y definiendo una política de ocupación sustentable de sus territorios y garantizando un lugar adecuado para todos los habitantes. Desde el punto de vista político, la ampliación de los espacios y actores de representación política, permitiría incorporar nuevos sujetos en las arenas de toma de decisiones de las políticas urbanas, generando un espacio para que múltiples proyectos de ciudad pudiesen expresarse y debatir la dirección y el sentido de las políticas.

en todas las regiones, realizando o apoyando más de 380 talleres que integraron a más de 22.000 participantes entre los cuales habían técnicos, gestores locales, líderes sociales, etc. El Ministerio también utilizó recursos propios o de socios en el ámbito del gobierno federal, para financiar la contratación de servicios por parte del municipio para la elaboración del Plan. Se apoyó financieramente la elaboración de los Planos Directores de aproximadamente un tercio de los 1.683 municipios obligados por ley.

3 T.L.: traducción libre de los textos citados. 
La implementación de esta agenda procuró incidir en el modelo de desarrollo urbano, construido a lo largo de cuatro décadas de intensa urbanización y caracterizado por la exclusión político-territorial de segmentos mayoritarios de habitantes. Procuró también incidir sobre el modelo de gestión del territorio y la definición de las políticas urbanas hacia la construcción de ciudadanía, más allá del aspecto normativo de los procedimientos político-electorales, sino promoviendo en el ámbito de cada territorio la producción de un sentido colectivo de uso y control del territorio (Paoli, 1995, p. 376).

\section{La lógica del desorden urbano}

En menos de 40 años (1940-1980), la población brasileña pasó de ser predominantemente rural a mayoritariamente urbana. Este movimiento, impulsado por la migración de un vasto contingente de personas pobres, se llevó a cabo en base a un modelo de desarrollo urbano que privó a los segmentos de bajos ingresos de las condiciones básicas de urbanidad y de inserción efectiva a la ciudad. Además de excluyente, el modelo de urbanización fue concentrador: $53,62 \%$ de la población vive en 253 municipios con más de 100.000 habitantes, de los cuales $80 \%$ forman parte de los 37 grandes aglomerados urbanos del país, de forma tal que se reproduce permanentemente un movimiento que concentra los incrementos económicos-demográficos en ciertos puntos del territorio, vaciándose los demás (Cuadro 1).

La concentración regional se repite a nivel intra-urbano ya que en cada punto del territorio donde hubo un gran crecimiento urbano, las calidades urbanísticas se acumulan de forma restrictiva, generando áreas con infraestructura de vivienda, negocios y de consumo para una minoría de la población urbana. Estas áreas, de mercado, se regulan a través de un extenso sistema de normas, contratos y leyes que tienen casi siempre como condición de base la propiedad privada, escriturada y registrada. Los terrenos que la ley permite urbanizar así como los financiamientos disponibles en el sistema de crédito inmobiliario, están reservados al estrecho círculo de los que tienen recursos y propiedad formal de la tierra.

DISTRIBUCIÓN DE LA POBLACIÓN BRASILEÑA POR GRUPOS DE MUNICIPIOS

\begin{tabular}{|c|c|c|c|c|c|c|}
\hline \multirow{2}{*}{$\begin{array}{l}\text { Municipios por } \\
\text { número de } \\
\text { habitantes }\end{array}$} & \multicolumn{2}{|c|}{$\begin{array}{c}\text { Población residente } \\
\text { (1991) }\end{array}$} & \multicolumn{2}{|c|}{$\begin{array}{l}\text { Población residente } \\
\qquad(2000)\end{array}$} & \multicolumn{2}{|c|}{$\begin{array}{c}\text { Población residente } \\
\text { (2007) }\end{array}$} \\
\hline & $\begin{array}{l}\text { total } \\
\text { absoluto }\end{array}$ & $\begin{array}{l}\% \\
\text { total }\end{array}$ & $\begin{array}{l}\text { total } \\
\text { absoluto }\end{array}$ & $\begin{array}{l}\% \\
\text { total }\end{array}$ & $\begin{array}{c}\text { total } \\
\text { absoluto }\end{array}$ & $\begin{array}{l}\% \\
\text { total }\end{array}$ \\
\hline Hasta 5000 & 2.537 .195 & 1,72 & 4.477 .347 & 2,64 & 4.492 .253 & 2,44 \\
\hline De 5001 a 10000 & 7.715 .054 & 5,25 & 9.356 .732 & 5,51 & 9.014 .356 & 4,90 \\
\hline De 10001 a 20000 & 18.420 .030 & 12,55 & 19.603 .512 & 11,55 & 19.996 .744 & 10,87 \\
\hline De 20001 a 50000 & 28.191 .796 & 19,20 & 28.832 .600 & 16,98 & 29.986 .945 & 16,30 \\
\hline De 50001 a 100000 & 19.232 .673 & 13,10 & 20.928 .128 & 12,33 & 21.847 .102 & 11,88 \\
\hline De 100001 a 500000 & 31.889 .220 & 21,72 & 39.628 .005 & 23,34 & 44.828 .150 & 24,37 \\
\hline Más de 500000 & 38.837 .821 & 26,45 & 46.973 .033 & 27,66 & 53.808 .731 & 29,25 \\
\hline Total Brasil & 146.823 .789 & $100 \%$ & 169.799 .357 & $100 \%$ & 183.974 .281 & $100 \%$ \\
\hline
\end{tabular}


Aunque no exista una estimación rigurosa del número total de familias y de hogares que viven en las favelas, conjuntos habitacionales irregulares, fraccionamientos clandestinos y de otras formas de asentamientos marcados por alguna precariedad urbanística o irregularidad administrativa y patrimonial, es posible afirmar que este fenómeno está presente en la mayoría de la red urbana brasileña. En el vasto y diverso universo conformado por 5.564 municipios brasileños, son raras excepciones las ciudades que no tienen una parte significativa de su población asentada precariamente ${ }^{4}$. Excluidos del marco regulatorio y de los sistemas financieros formales, los asentamientos precarios fueron auto-producidos por sus propios habitantes, con los medios que se encontraban a su disposición: salarios bajos, insuficientes para cubrir el costo de la vivienda (Oliveira, 1988; Maricato, 1996); falta de acceso a recursos técnicos y profesionales; y tierras vedadas o excluidas por la legislación ambiental y urbanística para el mercado inmobiliario formal. Es así que la ciudad fuera de la ciudad se construye en terrenos frágiles o áreas no permitidas para la urbanización, como por ejemplo sobre laderas escarpadas y áreas inundables, así como a través de grandes áreas de expansión periféricas sobre zonas rurales. Dichas zonas están eternamente desprovistas de infraestructura, de equipamientos y de servicios que caracterizan la urbanidad. Estos asentamientos, invisibles en los planos catastrales de las prefecturas y de las concesionarias de servicios públicos, e inexistentes en los registros de propiedad, tienen una inserción ambigua en las ciudades donde se localizan. Modelo dominante de territorialización de los pobres en las ciudades brasileñas, los asentamientos tienen una consolidación progresiva, siempre incompleta y totalmente dependiente de la acción voluntaria y discrecional del poder público, ya que no se encuadran en la semántica de las normas urbanísticas.

Al delimitar las fronteras que separan a los regulares-formales de los irregulares-informales, el modelo de exclusión territorial que define a la ciudad brasileña va más allá de la expresión de las desigualdades sociales y de ingreso, funciona como una suerte de engranaje de la maquinaria de crecimiento que al construir ciudades, reproduce desigualdades (Ferreira, 2007). En una ciudad con una división entre una parte legal, rica y con infraestructura, y otra ilegal, pobre y precaria, la población que está en la situación más desfavorable, termina teniendo mucho menos acceso a las oportunidades económicas y culturales que la ciudad ofrece. En paralelo, las oportunidades de crecimiento y desarrollo circulan en los espacios de aquellos que ya viven mejor.

Finalmente, la lógica del desorden se completa con el carácter depredador del modelo, condenando a la ciudad como un todo a un patrón no sustentable desde el punto de vista ambiental y económico, ya que impone pérdidas de calidad ambiental y externalidades negativas muy difíciles de recuperar para el conjunto mismo de la ciudad. En primer lugar, la territorialización de la concentración de las oportunidades en un fragmento de la ciudad, y la ocupación extensiva de sus periferias densas y distantes, imponen un patrón de circulación que depende

\footnotetext{
$4 \quad$ La investigación Perfil Municipal (MUNIC-IBGE, 2000) revela la presencia de asentamientos irregulares en casi $100 \%$ de las ciudades con más de 500.000 habitantes, y en $84 \%$ de las ciudades entre 100.000 y 500.000 . Aún en los municipios con menos de 20.000 habitantes, los asentamientos informales aparecen en el 30\% de los casos. De acuerdo a las estimaciones de IPEA, basadas en una metodología de UN-Habitat y en datos del Censo Demográfico, 40,5\% del total de los hogares urbanos brasileños, o lo que es lo mismo 16 millones de familias, se encuentran en esta condición -de las cuales 12 millones son de bajos ingresos.
} 
del transporte sobre ruedas y, por tanto, de un alto consumo energético potencialmente contaminante. Por otro lado, la ocupación de las áreas frágiles o estratégicas desde el punto de vista ambiental (como son los mantos de agua, los sistemas dunares o los manglares) son la consecuencia de un patrón de crecimiento en base a la apertura de los nuevos bordes, y de expulsión permanente de la población más pobre de las áreas ocupadas por el mercado.

Este patrón, expande los límites de la ciudad de manera fragmentada y a partir de iniciativas de propietarios de tierra, de fraccionadores, o arrasando y quitando tejido construido con el objetivo de acoger sus nuevos productos inmobiliarios dirigidos a parcelas solventes de habitantes urbanos. Finalmente, la ingeniería urbana mecánica que procuró transformar a las ciudades en una máquina de producción y circulación, trató a la geografía natural de la ciudad -tales como ríos, valles inundables, laderas- como un obstáculo a superar, aplanando, ganando tierras, re-encauzando las aguas, etc., y generando diseños que procuraban minimizar las pérdidas del mercado de suelo.

Evidentemente este modelo, que se inscribe en el orden administrativo que regula la ciudad, no fue producto de un pacto, ni fue construido en la esfera pública con quienes habitan el territorio. Su lógica está marcada por dos elementos constitutivos de nuestra cultura política: la distinción y ambigüedad entre lo público y lo privado, entre lo real y lo legal.

\section{Política urbana: entre lo público y lo privado, entre lo real y lo legal}

Ambigüedad -no ilegalidad- es una característica de la relación del territorio popular con la ciudad de los ciudadanos: "no se trata de una frontera fuera del Estado, de sus leyes y regulaciones públicas. Legal e ilegal, formal e informal, lícito e ilícito, es allí donde está imbricada la cuestión" (T.L. Telles, 2007, p. 515).

Dentro del modelo de la política urbana vigente en el país impera la "ambigüedad constitutiva", ampliamente identificada por los historiadores y cientistas políticos como característica de la política brasileńa; ambigüedad que "produce fórmulas combinatorias entre lo real, lo legal, lo público y lo privado, reinventando sus fronteras asi como trabajando hacia el mantenimiento de la misma" (T.L. Gomes, 1998, p. 502).

En el caso de la política urbana legal, esto representaría un poder centralizado y concentrado en un Estado moderno, asentado sobre bases impersonales y racionales, que se ejerce a través de una burocracia técnica. Su presencia en el escenario y en el imaginario político de la gestión urbana se da a través de un extenso corpus normativo, destallado y fragmentado desde el punto de vista institucional. En lo que concierne al campo de la gestión del territorio, éste se estructura en sectores (tales como habitacional, saneamiento, transporte, medio ambiente, urbanismo, patrimonio histórico, patrimonio público, etc.) con sus respectivos marcos regulatorios y burocracias que se emplazan en agencias públicas, autarquías y órganos de administración directa vinculados a las esferas municipales, estaduales y federales. El modelo de intervención federal en la política urbana apostó a la opción "sectorialista" desde inicios de los años '70, años de gestión centralizada y autoritaria de los gobiernos militares. En aquel momento, según uno de los planificadores involucrados en la tarea, era evidente el choque de 
dos concepciones: "una, buscando lidiar con el espacio brasileño con una manifestación completa en el territorio, y la otra, con una visión segmentada de lo urbano, entendida como sumatoria de vivienda, transporte, saneamiento básico, gestión administrativa y finanzas; visión que propiciaba de inmediato una acción sobre la politica urbana de los distintos grupos de intereses en cada uno de estos sectores. Esta visión sectorialista, fue la vencedora y por ende la visión global, por lo tanto geográfica, fue derrotada" (T.L. Souza 1999).

Esta fragmentación institucional, a la que se le atribuye constantemente la responsabilidad por la baja y ineficiente capacidad gerencial, la excesiva burocratización y el desorden de las ciudades, forma parte en realidad de una estrategia de "maximización de los intereses particulares de los burócratas, parlamentarios y empresarios (proveedores) (...) opción predominante para la articulación entre segmentos burocráticos y segmentos privados prestadores de servicios o proveedores de bienes (...) En este proceso de redes de influencia, es necesario aumentar aún más la intervención de las fuerzas políticas de apoyo a la coalición gobernante, que controlan la nominación de personas para ocupar los cargos considerados clave para el funcionamiento operativo de los programas" (T.L. Silva, 2003, pp. 36-38).

De esta manera, una de las formas que combinan lo público y lo privado se reproduce en el interior del mundo legal, donde el Estado se hace presente. Esta observación es importante ya que es común igualmente, atribuir el "desorden" de las ciudades a la "ausencia del Estado", sobre todo en los territorios populares. A nuestro entender, esta afirmación es falsa en la medida que si bien faltan bienes, servicios y espacios públicos en los territorios populares, éstos solo se construyen a partir de la presencia del Estado: "debemos destacar que estos barrios relegados son el producto de las políticas estatales en materia de vivienda, urbanismo y planificación. En el fondo, entonces, su surgimiento y consolidación son en esencia una cuestión politica" (T.L. Wacquant, 2007, p. 179).

Tanto para los sectores empresariales como para los "autoconstructores" del hábitat popular, la acción del Estado invirtiendo en urbanización o regulando el territorio es decisiva. Para el mercado formal de producción de ciudad, la relación con el aparato estatal se da a través de la producción y provisión de bienes cuya demanda proviene del propio Estado -tal es el caso de las empresas de obra pública y de concesionarios de servicios urbanos, como la recolección de basura, el transporte, entre otras (Marques, 2003)-. Asimismo, se da a través del establecimiento del marco regulatorio de las transacciones económico-jurídicas que ocurren en el mercado, de las leyes y normas establecidas en los distintos niveles de gobierno que afectan la competitividad y la rentabilidad de los productos del mercado, como la política tributaria sobre los inmuebles, las normas de uso y ocupación del suelo, las políticas de crédito inmobiliario, para citar algunas (Souza, 1999). "La actividad inmobiliaria, asi como cualquier otra actividad capitalista, incorpora un fuerte componente de riesgo. Eso significa que los emprendedores producen la ciudad adelantándose, y en lo posible dentro del vector general (seguro) de desplazamiento de las clases dominantes. El factor de riesgo se encuentra en el hecho que, evidentemente, nunca se puede saber si la demanda acompañará exactamente la oferta producida (...) Una coalición público-privada bien montada que canalice los recursos públicos para la modernización previa de determinados 'frentes inmobiliarios', puede disminuir sustancialmente, o incluso eliminar, estos riesgos" (T.L. Ferreira, 2007, p. 221). 
De esta forma, los sectores empresariales de la ciudad formal establecen conexiones privilegiadas con los sectores burocráticos de las agencias públicas, que tienen el control de los procesos de toma de decisiones sobre la inversión en infraestructura y urbanización, así como sobre las reglas del control urbanístico, garantizando reservas de suelo para expandir la producción de sus productos y rentabilidad más segura para sus inversiones.

Para los autoconstructores del hábitat popular, la acción del Estado es igualmente crucial. Esta relación, inmersa también en un terreno signado por la ambigüedad, se da a través del grado de tolerancia a las ocupaciones y demás actos de infracción de lo legal, establecidos en el marco jurídico por parte del aparato estatal. Se da también a través del grado de acceso a los bienes públicos -como infraestructura y servicios urbanos- provistos por el Estado. A pesar de que tanto para los sectores empresariales como para los autoconstructores del hábitat popular, la acción del Estado sobre lo urbano es esencial para la existencia y supervivencia de los mismos, estas relaciones se caracterizan por presentar asimetrías y gramáticas distintas.

La estrategia de privatización del control de la ciudad por parte del capital se vale de una "epistemología imperial" para construir su discurso, que descalifica y humilla, en nombre de la ciencia y la técnica, el conocimiento y el saber hacer de los demás grupos sociales (Boaventura, 2003, p. 14). Podemos tomar como ejemplo entre infinitos casos, el lenguaje de la planificación urbana, y más específicamente el lenguaje sobre el control y el uso del suelo en la ciudad. No es por casualidad que se trata de un código de alta complejidad y muy opaco, estructurado en base a la lógica económico-financiera de rentabilidad y de valorización de la inversión inmobiliaria. Su opacidad, por sí misma ya sería suficiente para privatizar el espacio de interlocución para aquellos que participan directamente en las redes de incidencia del aparato político-burocrático.

Las tipologías previstas por la normativa urbana y edilicia corresponden íntegramente a los productos disponibles en el mercado formal y privado (multifamiliar vertical, barrio cerrado, unifamiliar horizontal, etc.) y se destinan para ellos las mejores localizaciones urbanas y los mayores potenciales de aprovechamiento en planes directores y leyes de uso y ocupación del suelo. De esta manera se bloquea el acceso al suelo con infraestructura al mercado popular, generando allí un proceso de valorización que es capturado por los agentes privados.

Los mercados formales para medianos y altos ingresos, que se nutren de la escasez de urbanidad en la mayor parte de la ciudad, incorporan en su precio todo el valor generado por la inversión pública, manteniendo de esta manera sus altos precios y la exclusividad de sus productos. Por otro lado, estos incrementos de valorización inmobiliaria son poco tributados, ya que los impuestos prediales y territoriales que se imputan son, en la mayoría de las ciudades, bastante bajos $^{5}$ (Smolka, 2003). Esto es uno de los factores que mantienen la baja inversión en urbanización, si comparamos con la cantidad de riqueza producida principalmente en las grandes ciudades del país, dado que esta fuente de financiamiento extensamente utilizada en las ciudades del mundo capitalista avanzado se utiliza muy poco en Brasil, protegiendo la privatización de las ganancias inmobiliarias.

5 Según Smolka (2003), en América Latina el impuesto sobre la propiedad inmobiliaria representa menos del $0,5 \%$ del PBI, mientras que en países como Canadá y EEUU corresponden en promedio a 3 y $4 \%$ del PBI. 
En el territorio popular, la presencia del Estado se da sobre todo a través de la mediación política en la distribución de bienes y servicios públicos (Graham, 1990). Si consideramos que la mayor parte de las inversiones en urbanización ocurren a posteriori, o sea, cuando los barrios ya están ocupados, y consideramos que esta demanda tiene grandes dificultades en ser atendida, la disputa por el acceso a la inversión es muy fuerte y tiene un gran impacto político-electoral local. La condición de informalidad y/o ilegalidad de los asentamientos genera bloqueos al interior de los órganos burocráticos para reconocerlos como posibles de regularizar, lo que genera que esta demanda ocurra de forma selectiva y, generalmente, políticamente intermediada. La combinación de un proceso de urbanización de la pobreza e inserción precaria de estos habitantes de la ciudad, hace que los bienes y servicios que mejoran su condición de urbanidad se conviertan en una de las demandas populares más importantes. En torno a movilizaciones locales surgieron reivindicaciones organizadas con respecto a la vivienda, transporte, salud, saneamiento, educación, etc. Estas movilizaciones, activas desde los años '70 en el escenario de la política urbana, constituyeron los llamados movimientos sociales urbanos que, además de presionar para obtener bienes y servicios públicos para los asentamientos populares, trajeron nuevas formas de organización colectiva más allá de aquellas presentes en las formas clásicas de organización política, como los partidos, los sindicatos, las burocracias y los gobiernos (Paoli, 1995; Sader, 1988). Es así que en el seno de la transición democrática, una de las bases sociales más importantes del Movimiento por la Reforma Urbana se forjó en base a la presión y reivindicación por la obtención de una vivienda y urbanización como "la conquista de un lugar para que el ciudadano común pueda ejercer sus derechos, y una conquista de una figuración simbólica positiva y activa de los actores populares como interlocutores y participantes del espacio público" (T.L. Paoli, 1995, p. 50).

A lo largo de los ' 80 , con el retorno de las llamadas libertades democráticas -partidos, organizaciones sociales y de empresa libres, elecciones directas y voto universal para los cargos legislativos y ejecutivos en los tres niveles de gobierno- la relación entre el sistema político electoral y los movimientos sociales urbanos se tornó más compleja. Por un lado, el surgimiento de los partidos (sobre todo el PT - Partido de los Trabajadores) autodefinidos como partidos "de los movimientos sociales" aportaría para las instituciones de la democracia formal parte de las agendas de estos actores. Por otro lado, la lógica de la competencia político-partidaria también impregnó el universo de los movimientos, transformando su propia cultura, que había sido forjada en el ámbito de las Comunidades Religiosas de Base y de las pastorales de la iglesia católica, entonces (los ‘70) bajo una fuerte hegemonía de la teología de la liberación. Esta ecuación se tornó todavía más compleja si consideramos que la transición democrática en Brasil se llevó a cabo a través de un pacto restrictivo e intra-élites, que preservó las reglas del juego de representación de intereses, reproduciendo la tradición de los mandatos individuales que se articulaban en networks (redes) y una maquinaria político-electoral fuertemente entrelazada con la maquinaria estatal (Avritzer, 2003).

A la izquierda y a la derecha del espectro político partidario, tanto los debutantes que emergieron del movimiento sindical y popular, como los viejos caciques de la sociedad política tendrían que competir por el voto popular y, por ende, de una manera u otra, relacionarse con los reclamos de inserción en la ciudad tanto de la población organizada en movimientos como de aquella no organizada. Es así que la inversión en urbanización, la tolerancia, la autorización e incluso 
la promoción de asentamientos precarios se convirtieron en un potente dispositivo electoral con grandes posibilidades de retorno político para sus promotores. Tal como afirmáramos, el territorio popular está permanentemente atravesado por el mundo de la política que espera allí recibir el premio de parte de aquellos que fueron selectivamente beneficiados con recursos públicos por su intermedio (Avelino, 1994; Carvalho, 1997).

Para nuestro análisis, no es relevante el hecho de encuadrar o no esta práctica como clientelista; sino que nos resulta más importante señalar cuál fue su peso en la política urbana y en nuestro modelo de democracia. Para entender este mecanismo, consideramos necesario analizar los orígenes de los recursos públicos destinados al desarrollo urbano en general, y a la urbanización de los asentamientos precarios en particular, y la forma en que se dan los procesos de toma de decisiones sobre su utilización en las ciudades.

\section{La inversión en urbanización: ¿quién decide?}

La Constitución promulgada en 1988 reforzó la autonomía de los gobiernos municipales, pasando éstos a asumir un rol de mayor importancia en la prestación de servicios. El texto constitucional aprobado fortaleció financieramente a los municipios, hecho que se debió más por el aumento en la participación de los mismos en las transferencias constitucionales de otros entes federativos que por el aumento de su capacidad tributaria. De hecho, la Constitución innovó muy poco en relación a las competencias tributarias municipales. Los municipios cuentan con tributos propios que se aplican sobre actividades mayoritariamente urbanas: el Impuesto sobre la Propiedad Predial y Territorial Urbana (IPTU) y el Impuesto sobre Servicios de Cualquier Índole (ISS). Sin embargo, la gran mayoría de los municipios del país basan su economía en el medio rural (Bremaeker, 2006). Más de 70\% de los municipios brasileños obtienen casi $90 \%$ de sus ingresos a través de transferencias de otros niveles de gobierno. $\mathrm{Ni}$ siquiera los dos municipios más poblados del país (San Pablo y Río de Janeiro) superan 40\% de sus presupuestos con recursos propios (Bremaeker, 2008, p. 25) (Cuadro 2).

Teniendo en cuenta que la mayor parte de los ingresos de transferencia obligatoria y automática ${ }^{6}$ cubren solamente el costo de la maquinaria municipal, incluyendo la prestación de servicios sociales básicos previstos constitucionalmente, la mayoría de los municipios depende de las llamadas transferencias voluntarias y/o del acceso a operaciones de crédito para poder realizar obras de inversión en infraestructura urbana.

En el período analizado en este artículo, "la orientación del Poder Ejecutivo federal fue mantener un sistema centralizado regido por una burocracia frágilmente aislada. El gobierno federal mantuvo bajo control las líneas de crédito y el acceso a los recursos" (T.L. Arretche, 2000, p. 124). Para los municipios el acceso a estos recursos es dependiente de las relaciones entre el gobierno local y las instancias estaduales y federales de toma de decisiones.

\footnotetext{
6 Son transferidos mensualmente a los municipios recursos de un Fondo Federal (FPM), distribuidos en base a la población y Estado a que pertenecen. Recursos para la salud y educación son también transferidos a las municipalidades en base respectivamente a la población y rol en el Sistema Único de Salud (SUS) y el número de niños matriculados en la red de enseñanza publica municipal (FUNDEF).
} 
Cuadro 2

INGRESOS MUNICIPALES SEGÚN TIPO DE MUNICIPIO

\begin{tabular}{lccccc}
\hline $\begin{array}{c}\text { Municipios por } \\
\text { número de } \\
\text { habitantes }\end{array}$ & $\begin{array}{c}\text { Total de número de } \\
\text { municipios por } \\
\text { grupos de habitantes }\end{array}$ & $\begin{array}{c}\text { \% } \\
\text { Transferencias } \\
\mathbf{( \% )}\end{array}$ & $\begin{array}{c}\text { Ingresos } \\
\text { Tributarios } \\
\mathbf{( \% )}\end{array}$ & $\begin{array}{c}\text { Otros } \\
\text { Ingresos } \\
\mathbf{( \% )}\end{array}$ \\
\hline Hasta 5 000 & 1.371 & $24,64 \%$ & 93,54 & 2,63 & 4,83 \\
De 5 001 a 10 000 & 1.290 & $23,18 \%$ & 89,89 & 4,13 & 5,98 \\
De 10 001 a 20 000 & 1.292 & $23,22 \%$ & 89,38 & 4,87 & 5,75 \\
De 20 001 a 50 000 & 1.033 & $18,57 \%$ & 83,46 & 7,44 & 9,10 \\
De 50 001 a 100 000 & 311 & $5,59 \%$ & 75,40 & 12,57 & 12,03 \\
De 100 001 a 500 000 & 231 & $4,15 \%$ & 62,76 & 15,82 & 21,42 \\
Más de 500 000 & 36 & $0,65 \%$ & 40,69 & 39,80 & 19,51 \\
Total & $\mathbf{5 . 5 6 4}$ & $\mathbf{1 0 0 , 0 0 \%}$ & & & \\
\hline
\end{tabular}

Fuente: Bremaeker, F. (2008

Las posibilidades de acceso a financiamiento para los municipios estuvieron empero bastante restringidas en función de la política de ajuste de las cuentas públicas y, en particular, a partir de la Ley de Responsabilidad Fiscal; el endeudamiento municipal estuvo bastante controlado por las burocracias de control fiscal de la Unión, dejando como opción para los municipios solamente las transferencias voluntarias (Alston, Melo, Mueller y Pereira, 2005, p. 40) ${ }^{7}$. Estas se dan a través de convenios entre los municipios y los gobiernos estaduales o federal, y se originan a través de un proceso de selección realizado por el Poder Ejecutivo (llamado Presupuesto Programable) o por el Poder Legislativo (a través de las enmiendas parlamentarias). Las enmiendas pueden ser colectivas (regionales o estatales) o individuales. En el caso de las enmiendas individuales, normalmente se fija en el Parlamento un valor previo que el mismo puede asignar a inversiones en cualquier sector.

A pesar que todo el proceso de definición y asignación de presupuesto esté impregnado de transacciones políticas, la literatura (en el sentido común) acostumbra atribuir al Congreso la prerrogativa de enmendar el presupuesto y en particular las enmiendas individuales, cumpliendo el rol de "engranajes centrales de un proceso que se sostiene sobre el individualismo de los politicos, y que da lugar a una distribución clientelista y localista de los recursos públicos" (T.L. Limongi y Figueiredo, 2005, p. 737).

Sin embargo, los autores citados anteriormente, entre otros, demostraron que el Poder Ejecutivo mantiene el control rígido de todo el proceso de elaboración y ejecución presupuestal a través de normas de procedimientos institucionales que no permiten al Poder Legislativo desfigurarlo ${ }^{8}$

\footnotetext{
$7 \quad$ La Ley de Responsabilidad Fiscal (LRF), aprobada en 2000, establece exigentes controles sobre el gasto, ex ante y ex post. La LRF define detalladamente las reglas presupuestales y fiscales para el endeudamiento del sector público así como para operaciones de créditos y rendición de cuentas.

8 Estos mecanismos van desde la característica autorizadora del presupuesto -y no impositivo-, lo que permite una gran discrecionalidad en su ejecución, a través del control del flujo del gasto -llamado "contigenciamiento"-,
} 
(Alston, Melo, Mueller y Pereira, 2005). "Las enmiendas individuales no son privilegiadas por el Legislativo (...). Las enmiendas individuales representan una pequeña parte de la intervención legislativa en la asignación final de los recursos, y ocurre sin la intervención del Poder Ejecutivo (...) Al ejecutar los recursos asignados por parlamentarios mediante enmiendas individuales, el Poder Ejecutivo no cede a presiones y no deja de ejecutar su agenda. La asignación de recursos por parte de los legisladores, es complementaria y no contraria a aquella hecha por el Ejecutivo" (T.L. Limongi y Figueiredo, 2005, p. 776).

La proporción del presupuesto federal destinado a las enmiendas individuales se ha mantenido estable, al menos desde 1997, y es alrededor de $2 \%$ del total, con pequeńas variaciones positivas en 2001 y 2004. Asimismo, el número total de enmiendas se ha mantenido relativamente estable -alrededor de 8.000 por ciclo presupuestal- así como la proporción de enmiendas individuales en relación con las enmiendas colectivas - alrededor de 90\% (SIAFI 2007). La continuidad, en mayor o menor medida, del perfil de las enmiendas individuales y su rol en el presupuesto público a lo largo de los mandatos presidenciales que tuvieron claramente agendas distintas, demuestra la alta funcionalidad política de este mecanismo a pesar de la poca relevancia dentro del foco de las agendas. Este mecanismo de bajo costo puede, en ciertas coyunturas específicas, presentar alta rentabilidad desde el punto de vista de la gobernabilidad (Pereira y Mueller, 2002).

A pesar de tratarse de valores pequeños, la enmienda individual sellada puede tener impactos positivos en el éxito electoral y la sobrevivencia política de los parlamentarios. Si bien desde el punto de vista de los grandes objetivos de la coalición gobernante las enmiendas tienen poca importancia, en el ámbito de la competencia política interna del municipio, que es la base fundamental para definir la reelección de un parlamentario, este mecanismo puede ser trascendente. "El llamamiento electoral junto a los electores se hace justamente en nombre de la capacidad del candidato para intermediar recursos públicos para la comunidad”' (T.L. Avelino, 1994, p. 238).

Si tomamos en cuenta las reglas actuales de organización partidaria y de competencia electoral, así como los costos cada vez mayores de las campañas electorales, los parlamentarios que deseen garantizar su sobrevivencia política necesitan no solo mecanismos de acceso a la distribución de los recursos públicos sino también alternativas de financiamiento de sus campańas. El control de los puestos clave en la maquinaria estatal, que se encuentran en condiciones de incidir en las reglas de contratación de servicios y obras, así como la garantía de flujo de recursos para alimentar dicha maquinaria, pueden encontrar respuesta en esta doble función: la de provocar posibles retornos electorales positivos de parte de los beneficiarios directos de las obras o servicios, así como la de recibir posibles premios de parte de los contratistas en forma de donaciones para la campaña. No es un hecho casual que el área de desarrollo urbano -hoy gestionada por el Ministerio de las Ciudades- haya sido, conjuntamente con el área de la salud, la que más recibe enmiendas provenientes de los congresistas (Cuadro 3).

hasta la existencia de instrumentos como el crédito suplementario, especial o extraordinario, que permite alteraciones durante la ejecución. 
Si bien para el presupuesto federal el porcentaje que representan las enmiendas (incluso las colectivas) no es muy relevante en relación al total, para el Ministerio de las Ciudades éstas representan más de $50 \%$ del presupuesto aprobado y más de $80 \%$ del presupuesto ejecutado (SIAFI, 2006). Se trata de recursos para la construcción de viviendas, pavimentación de calles, canalización de aguas, reforma y acondicionamiento de espacios públicos. Básicamente, obras de urbanización generalmente dirigidas a consolidar asentamientos precarios de las ciudades del país. Por su lado, los rubros presupuestales de "apoyo al desarrollo urbano en municipios de menor tamaño" y de "apoyo al desarrollo urbano en municipios de gran tamaño" dan marco a las enmiendas colectivas. Varias de estas enmiendas colectivas, provenientes de bancadas estatales y por lo tanto destinadas de forma genérica a los municipios de un Estado, son una verdadera sumatoria de enmiendas individuales disfrazadas destinadas a solucionar pleitos de obras de urbanización de parlamentarios que sobrepasan los límites establecidos por las enmiendas individuales. Por último, se definen como enmiendas (habitualmente colectivas) los recursos federales sellados para grandes obras de urbanización tales como obras viales y sistemas de transporte colectivo como los metros o subtes.

Sin embargo, buena parte del proceso de toma de decisiones sobre la política urbana se da internamente en el juego político-electoral, en particular en lo que concierne a las inversiones en obras y ampliación de servicios urbanos. Este hecho nos ayuda a entender alguna de las características de la política urbana, y cómo ésta bloquea las tentativas de implementación de una agenda de reforma hacia la implementación de un proceso de planificación consensuada en la esfera pública. El área de desarrollo urbano es especialmente susceptible a estas prácticas dado que las asignaciones de los recursos son determinadas geográficamente y micro-inversiones en las periferias contribuyen a sustentar los mandatos a través de sucesivas elecciones. Los pequeños valores presupuestales en cuestión, insuficientes para garantizar condiciones de urbanidad básica, presentan, sin embargo, resultados visibles a corto plazo y por ende posibilidades reales de retribución por parte del electorado. Los actores políticos, en particular aquellos relacionados con el juego político partidario, están en general más interesados por las consecuencias de sus acciones a corto plazo dados los tiempos de la política electoral. "Agendas complejas y grandes reformas institucionales, con efectos necesariamente de largo plazo, movilizan apoyos de estos actores sólo si ganasen gran relevancia politica, o si éstos no vieran amenazada, a corto plazo, la retribución del elector" (T.L. Pierson, 2000).

Por un lado, se aseguran las bases populares a través del control de la distribución selectiva e individual de los beneficios, y por el otro se garantiza la sustentación política de las coaliciones de gobierno junto a las élites y el poder económico a través de la inversión en grandes obras (y regulación urbanística) articuladas para la creación de nuevos frentes de expansión inmobiliaria. Este es el modelo de Estado y sistema político que componen lo que hemos llamado lógica del desorden, que se puso en movimiento en la fase urbano-industrial de nuestro desarrollo urbano y que fue construido en el seno de la llamada "transición democrática". Su comprensión es necesaria para explicar las restricciones y obstáculos para la implementación de una agenda de reforma urbana; sin embargo es necesario también focalizar nuestro análisis sobre las transformaciones profundas que ocurrieron en las ciudades en los años ' 90 por el impacto de la globalización. 
ENMIENDAS PARLAMENTARIAS SEGÚN MINISTERIOS DEL GOBIERNO FEDERAL

\begin{tabular}{|c|c|c|c|c|c|c|c|c|}
\hline \multirow{3}{*}{ Órgano } & \multicolumn{4}{|c|}{2004} & \multicolumn{4}{|c|}{2005} \\
\hline & \multicolumn{2}{|c|}{ Individuales } & \multicolumn{2}{|c|}{ Colectivas + Relator } & \multicolumn{2}{|c|}{ Individuales } & \multicolumn{2}{|c|}{ Colectivas + Relator } \\
\hline & QTD & $\begin{array}{c}\text { Val. Aprob. } \\
\text { Final }\end{array}$ & QTD & $\begin{array}{l}\text { Val. Aprob. } \\
\text { Final }\end{array}$ & QTD & $\begin{array}{c}\text { Val. Aprob. } \\
\text { Final }\end{array}$ & QTD & $\begin{array}{c}\text { Val. Aprob. } \\
\text { Final }\end{array}$ \\
\hline $\begin{array}{l}\text { Ministerio de } \\
\text { Salud }\end{array}$ & 3171 & 733.600 .644 & 882 & 9.660 .890 .962 & 2261 & 571.816 .650 & 83 & 1.261 .053 .209 \\
\hline $\begin{array}{l}\text { Ministerio de las } \\
\text { Ciudades }\end{array}$ & 859 & 188.894 .750 & 132 & 677.301 .778 & 1468 & 515.259 .500 & 115 & 1.396 .003 .773 \\
\hline $\begin{array}{l}\text { Ministerio de } \\
\text { Educación }\end{array}$ & 418 & 68.411 .000 & 93 & 1.570 .654 .559 & 388 & 72527.000 & 47 & 948.113 .583 \\
\hline $\begin{array}{l}\text { Ministerio del } \\
\text { deporte }\end{array}$ & 534 & 95.548 .000 & 31 & 143.199 .395 & 736 & 200.987 .500 & 20 & 143.470 .000 \\
\hline $\begin{array}{l}\text { Ministerio de } \\
\text { Integración } \\
\text { Nacional }\end{array}$ & 292 & 76.922 .300 & 184 & 864.827 .242 & 242 & 86.219 .700 & 115 & 1.404 .713 .900 \\
\hline $\begin{array}{l}\text { Suma total de } \\
\text { enmiendas por } \\
\text { periodo }\end{array}$ & 7162 & 1.468 .810 .000 & 2027 & 20.806 .967 .177 & 7513 & 2.063 .010 .000 & 887 & 15.874 .322 .007 \\
\hline
\end{tabular}

\begin{tabular}{|c|c|c|c|c|c|c|c|c|}
\hline \multirow{3}{*}{ Órgano } & \multicolumn{4}{|c|}{2006} & \multicolumn{4}{|c|}{2007} \\
\hline & \multicolumn{2}{|c|}{ Individuales } & \multicolumn{2}{|c|}{ Colectivas + Relator } & \multicolumn{2}{|c|}{ Individuales } & \multicolumn{2}{|c|}{ Colectivas + Relator } \\
\hline & QTD & $\begin{array}{l}\text { Val. Aprob. } \\
\text { Final }\end{array}$ & QTD & $\begin{array}{l}\text { Val. Aprob. } \\
\text { Final }\end{array}$ & QTD & $\begin{array}{l}\text { Val. Aprob. } \\
\text { Final }\end{array}$ & QTD & $\begin{array}{l}\text { Val. Aprob. } \\
\text { Final }\end{array}$ \\
\hline $\begin{array}{l}\text { Ministerio de } \\
\text { Salud }\end{array}$ & 2744 & 1.121 .892895 & 266 & 4.127 .781 .032 & 2889 & 1.242389 .162 & 113 & 2573.411 .286 \\
\hline $\begin{array}{l}\text { Ministerio de las } \\
\text { Ciudades }\end{array}$ & 1218 & 582.536 .540 & 122 & 1.194 .612 .132 & 1386 & 740.213 .668 & 106 & 1.794 .866 .505 \\
\hline $\begin{array}{l}\text { Ministerio de } \\
\text { Educación }\end{array}$ & 465 & 94.659 .977 & 221 & 1.834 .449 .736 & 468 & 145.411 .420 & 250 & 2104.701 .622 \\
\hline $\begin{array}{l}\text { Ministerio del } \\
\text { deporte }\end{array}$ & 732 & 258.525 .255 & 28 & 498.673 .011 & 631 & 266.267 .500 & 15 & 216.995 .000 \\
\hline $\begin{array}{l}\text { Ministerio de } \\
\text { Integración } \\
\text { Nacional }\end{array}$ & 186 & 74.244 .540 & 117 & 1.333 .670 .416 & 194 & 125.269 .216 & 109 & 1.633 .590 .838 \\
\hline $\begin{array}{l}\text { Suma total de } \\
\text { enmiendas por } \\
\text { periodo }\end{array}$ & 7789 & 2943.223.501 & 1404 & 45.134 .068 .875 & 8024 & 3.510 .344 .000 & 1197 & 18.150 .145 .880 \\
\hline
\end{tabular}




\section{Fin de siglo: de la pobreza a la violencia}

El debate así como la literatura sobre las transformaciones urbanas que ocurrieron bajo la égida de esta nueva fase del capitalismo es amplio y traspasa los límites de este artículo el reproducirlo. Resaltamos aquí su impacto en el campo del ordenamiento urbano. Señala Wacquant sintéticamente (2007, p. 168): "De la mano de la modernización económica acelerada, provocada por la reestructuración global del capitalismo, la cristalización de una nueva división internacional del trabajo (fomentada por la velocidad frenética de los flujos financieros...) y el desarrollo de nuevas industrias de uso intensivo del conocimiento basadas en revolucionarias tecnologías de la información y generadoras de una estructura ocupacional dual, se produce la modernización de la miseria: el surgimiento de un nuevo régimen de desigualdad y marginalidad urbana".

En el caso brasileño, los efectos de estas transformaciones se sintieron sobre todo en las metrópolis, y especialmente en aquellas que se originaron durante el capitalismo fordista. Es allí donde las esperanzas de modernización e integración, a través del empleo formal así como de una trayectoria de mejoría y progreso permanente (acceso a la casa propia, a la educación y al bienestar) alimentaron las identidades colectivas, fertilizando las luchas por la inclusión territorial y la agenda de la reforma urbana.

En los años '90, el desempleo -intensificado por las políticas de ajuste estructural que impusieran una limitación el gasto público, reduciendo las posibilidades de distribución de beneficios- transformó la geografía de la pobreza urbana y de la vulnerabilidad social, con profundos impactos en la dinámica de cohesión social en el territorio popular y en las relaciones reales y simbólicas que éste establece con el conjunto de la ciudad (Telles, 2007; Santos Jr. y Ribeiro, 2003).

Estas transformaciones introdujeron nuevas variables a la estructuración de la ciudad, principalmente en las regiones metropolitanas y en los grandes centros industriales. Las grandes áreas de producción fordistas se sustituyeron paulatinamente por una economía de flujos, desterritorializándose y dejando en el camino grandes áreas urbanas vacías, y muchas veces contaminadas. El territorio popular se densificó sobre una base urbanística frágil y tosca, fruto de intervenciones fragmentadas, inconexas y discontinuas, definidas y ejecutadas bajo la lógica y el calendario políticos. El espacio metropolitano de la era industrial también se transformó, expandiéndose hacia las zona rurales, esparciendo enclaves como barrios cerrados, hipermercados y shopping-centers (Santos Jr., 2007).

La antigua dualidad centro-periferia se deshace, dando lugar a una nueva: lugares seguros versus lugares violentos. La ocupación de los asentamientos precarios por el comercio minorista de drogas impuso una sociabilidad nueva en estos territorios, violenta, implementada en paralelo a los aparatos de seguridad monopolizados por el Estado. Aunque apenas presente en algunos de los asentamientos precarios del país, la territorialización de las favelas por parte del tráfico de drogas ha contribuido a construir en el imaginario colectivo urbano la identificación de todas las favelas y periferias precarias del país como lugares violentos (T.L. Wacquant, 2007, p. 178). 
Sin embargo, el impacto de esta configuración va más allá de los efectos de profundización y reconfiguración de la segregación socio-espacial, y limita la permeabilidad entre los territorios populares y el resto de la ciudad. Por otro lado, frente a esta formación de enclaves fuera del control territorial estatal se opone el otro extremo del espectro socio-económico: la auto-segregación de las élites y de las clases medias que generan por su parte territorios también fuera del alcance del control del Estado (Souza, 2005). Lugares seguros son identificados como aquellos espacios exclusivos y cerrados, en los cuales la multiplicidad de la ciudad no logra penetrar. Se caracterizan por estar cercados, enrejados y con altos muros, protegidos por dispositivos electrónicos y por un ejército de seguridad privada. Sus espacios colectivos están vigilados por cámaras y circuitos cerrados de TV.

Entre estos dos polos, la ciudad de las calles que se estructura a partir de espacios y equipamientos públicos agoniza, expuesta y desprotegida por no contar ni con comandos o milicias, ni con los aparatos sofisticados de los ejércitos de la seguridad privada. Por su parte, el mercado tiene la capacidad inmediata de traducir este imaginario en valores del suelo y de productos inmobiliarios, y consolida fuera de la ciudad, a través de estrategias de marketing, el deseo de un paraíso comunitario, homogéneo e inmune a los conflictos y tensiones. La fragmentación socio-política territorial resultante de esta reconfiguración representa no sólo una nueva forma de estructuración urbana, sino también un desafío para la noción de ciudad en sí misma, en la medida que "la violencia, la segregación, y la auto segregación extremadas producen la erosión bastante real de las condiciones del ejercicio de la ciudadanía y la búsqueda de autonomia, requisitos para un desarrollo socio-espacial' (T.L. Souza, 2005, p. 205).

A pesar de la importancia de la lógica de violencia -sobre todo en el contexto de las grandes ciudades- ésta no constituye en absoluto el único elemento limitador de las posibilidades de establecimiento de una civilidad y urbanidad inclusivas, basadas en el reconocimiento de los derechos de la ciudadanía9. La versión neo-liberal de la agenda de la Reforma del Estado trajo consigo la revalorización del comunitarismo y la acción directa de la sociedad civil prescindiendo del Estado al interior de las políticas urbanas y los procesos sociales. Tal como se ha mencionado anteriormente, también introdujo nuevos contenidos al discurso participacionista de los años ' 80 .

Es así, de acuerdo con Vera Telles (2007, p. 501), que el universo popular de las periferias pobres de la ciudad es "también rediseñado por un intrincado y multifacético juego de actores (...) los programas sociales se multiplican en las periferias, y en torno de ellas van proliferando asociaciones llamadas comunitarias que tratan de convertir la lógica de gestión del llamado emprendimiento social al acreditarse como socias de los poderes públicos locales y disputar recursos de fundaciones privadas (también llamada filantropia empresarial) y de agencias multilaterales. Todo esto interactuando con una multitud de prácticas asociativas, como los movimientos de vivienda y sus articulaciones politicas, partidos y sus contactos locales, las iglesias evangélicas (también en proliferación) y sus comunidades de fieles, y evidentemente la casi omnipresencia de las organizaciones

$9 \quad$ Utilizamos aquí el concepto de civilidad (o civismo) en el sentido empleado por Richard Sennett (1989), como la posibilidad de compartir un territorio heterogéneo y diverso a partir del reconocimiento y respeto de los derechos ajenos y la consideración mutua. 
no gubernamentales vinculadas a redes de naturaleza diversa y de variado tamaño. Es alli donde se configura un mundo social atravesado por toda suerte de ambivalencias, de formas (viejas y nuevas) de clientelismo y reinvenciones politicas, convergencias y disputas, prácticas solidarias y aciertos (o desaciertos) con mafias locales y tráfico de drogas".

Una especie de confluencia perversa aproximó -a nivel discursivo- proyectos políticos que apuntaban en direcciones opuestas. Tanto el proyecto democrático participativo, que tuvo origen en el enfrentamiento con el autoritarismo y continuó en la dirección de la construcción de una institucionalidad que correspondiese a una nueva gramática social y cultural, como el proyecto de reducción del Estado y despolitización de la sociedad civil transformándola en Tercer Sector (junto al Estado y al Mercado), pasaron a utilizar categorías comunes tales como participación y ciudadania (T.L. Paoli, 2002, p. 404).

La homogeneidad del vocabulario oculta las diferencias y reduce los antagonismos, abriendo así los canales por donde avanzan las concepciones neo-liberales (Dagnino, Olviera y Panfichi, 2006, p. 17). De esta manera, funcionan con maniobras ejecutadas por el liberalismo para afirmarse como el único protagonista legítimo del campo anti-autoritario: "la mejor manera de conseguir esto consiste en abrir una enorme boca de cocodrilo para engullir e incorporar las virtudes tipicas de los demás miembros de su propia familia, quitándoles sus titulos de identidad" (T.L. Martins, 2003, p. 629).

La redefinición de la noción de participación y ciudadanía acentúa la fragmentación sociopolítica territorial, contribuyendo a diluir aquello que constituye la promesa de un proyecto democrático integral: el acceso pleno y universal a los derechos civiles, políticos, económicos y sociales.

\section{Notas Finales}

A partir de la convocatoria del Ministerio de las Ciudades, más de 4.000 municipios brasileños promovieron procesos locales de discusión pública sobre el desarrollo urbano, tanto a través de Conferencias Municipales, como a través de la elaboración de los Planes Directores Participativos, y de la participación en Consejos constituidos a partir de estos procesos. Aquellos que participaron en estos espacios vivieron una diversidad muy rica de experiencias, ya que estos espacios se diseminaron por todo el país, articulando actores e incidiendo sobre las configuraciones político-territoriales más diversas.

En muchas ciudades, se realizaron por primera vez debates públicos sobre temas de política urbana; en otras se trató simplemente de un procedimiento formal, a través de la convocatoria a una audiencia pública y su registro en acta, de manera que el poder político local pudiera seguir participando en el juego de la disputa federativa por recursos para urbanización, sin ser acusado -o eventualmente castigado- por infringir la ley.

Descentralizar la gestión del uso del suelo sin establecer una organización del Estado que permita la coordinación de políticas entre los diferentes sectores y niveles de gobierno, es condenar la práctica de la planificación urbana local a un ejercicio retórico. Igualmente sucede si falta una 
capacidad local instalada que viabilice la implementación de una estrategia urbana de largo plazo. Este ejercicio retórico, así como otros corpus normativos, se manejan con ambigüedad constitutiva: se trata de una ley que puede o no ser implementada, y depende de la voluntad y capacidad del poder político local introducirla en el amplio campo de las intermediaciones del sistema político.

Aunque el Estatuto de la Ciudad establezca la obligatoriedad de vincular los ciclos presupuestales municipales posteriores a la aprobación de Planos Directores a sus definiciones y propuestas, en lo que concierne al desarrollo urbano, los ámbitos de decisiones locales tienen poca autonomía real sobre estas inversiones -sean ellas de origen participativo o no-. Esto se debe a que el área de desarrollo urbano en el Estado brasileño continua estando estructurada en base a burocracias altamente sectorizadas y centralizadas, que funcionan a través de procesos de toma de decisiones bastante impregnados por los intereses de actores económicos y políticos que dependen de él para sobrevivir.

Sin embargo, a partir de lo anteriormente expresado no queremos afirmar que una propuesta de reforma tributaria y de desarrollo del modelo federativo, capaz de sustentar gobiernos locales con capacidad administrativa, técnica y económica para gestionar su territorio, sea condición necesaria y suficiente para potenciar procesos de planificación que se pacten en la esfera pública. Las gramáticas políticas que conforman las relaciones Estado-Sociedad en Brasil atraviesan los ámbitos federativos a través de un intrincado conjunto de relaciones que involucran grupos municipales, estatales y federales, y se basan en una jerarquía de vínculos y favores que incluyen cargos en el gobierno, así como acceso a recursos y prestaciones de bienes y servicios. Los partidos políticos desempeñan un papel crucial en la conexión de estas gramáticas con las normas universalistas de la democracia representativa brasileña, de manera tal que los corredores en el mercado de votos (que a su vez asegura posiciones en el mercado de proveedores del Estado) son muchas veces cuadros dentro de la maquinaria partidaria o funcionarios de los gabinetes legislativos.

Cuatro gramáticas han sido ampliamente identificadas como características de la cultura política brasileña: el clientelismo, el corporativismo, el aislamiento burocrático y el universalismo de procedimientos (Nunes, 1997). A estas características es necesario agregar otras dos que parecen también atravesar las relaciones políticas en Brasil: la ambigüedad y la brutalidad, versión salvaje del autoritarismo. Lejos de estar caracterizando prácticas que se dan solamente en el aparato estatal, al relacionarse con la sociedad en general, estas gramáticas impregnan y estructuran las relaciones de poder también al interior de la sociedad civil. Si se examinan las relaciones políticas que se dieron al interior de la construcción e implementación del Consejo Nacional de las Ciudades, así como las relaciones del mismo con el Ministerio y con el gobierno en general, es posible identificar claramente que más allá de la innovación político-cultural, allí también estuvieron presentes el clientelismo, el corporativismo, la ambigüedad y la truculencia de manera vigorosa. Refutamos así la visión simplista y romántica de la sociedad civil considerada como polo de virtudes democratizadoras y al Estado como "encarnación del mal" (Dagnino, Olviera y Panfichi, 2006, p. 16). 
En los Consejos, así como en el interior del Estado y en el amplio campo que constituyen las relaciones de poder en la sociedad brasileña, los proyectos políticos, de democracia y de país son múltiples y se encuentran en permanente disputa. Al mismo tiempo que podemos identificar en la experiencia de la elaboración de los Planos Directores y de la actuación del Consejo Nacional de las Ciudades, la fuerza conservadora de una cultura política fuertemente arraigada en la relación Estado-actores sociales, también debemos señalar los elementos de innovación y ruptura que estos procesos trajeron consigo.

Desde luego, el contenido de los debates que se abrieron en las ciudades, a pesar de estar pautados por el Ministerio y previamente negociados por el Consejo Nacional, incorporaron cuestiones y proyectos locales, produciendo nuevas articulaciones políticas e introduciendo nuevas cuestiones en la agenda de la política urbana de cada ciudad ${ }^{10}$.

La idea de la construcción pública y colectiva de un proyecto de ciudad, cuyos pilares se basen en la función social presentada por el Estatuto de las Ciudades y promovida en la Campaña de los Planos Directores tropezó, como ya analizamos, con el blindaje y hermetismo de la semántica operada por el lenguaje de la planificación urbana, sobre todo en las grandes ciudades, con la fragmentación socio-política del territorio urbano. Sin embargo, no fueron pocas las ciudades donde movimientos y organizaciones de la sociedad civil intervinieron con propuestas y lograron, a favor o en contra de los representantes del poder ejecutivo o legislativo, incluir instrumentos de democratización de la gestión del territorio. Muchas veces esto se llevó a cabo por medio de la movilización del Poder Judicial y sobre todo a través de la movilización del Ministerio Público. Aun para aquellos que lograron construir planos mínimamente consensuados, todavía les resta el gran desafío de la implementación de los mismos. Más que una supuesta voluntad politica para implementar los planes directores, los gobiernos locales carecen claramente de incentivos para hacerlo, ya que como se ha analizado, los procesos de toma de decisiones sobre las inversiones y el destino de la ciudad está estructurado en torno a otras lógicas dentro del actual modelo federativo y sistema político brasileños.

Por lo tanto, el avance de la Reforma Urbana en Brasil carece, más allá del fortalecimiento de los espacios de ejercicio de la democracia directa y de control social -ejes estructuradores tradicionales de su agenda-, de la formulación de un proyecto de reforma política y de desarrollo del actual modelo federativo de gobierno y gestión urbana, elementos fundamentales para la consolidación de la democracia plena en el país.

\section{Referencias bibliográficas}

Alston, L.; Melo, M.; Mueller, B. \& Pereira, C. (2005). Who decides on public expenditures? A political economy analysis of the budget process. The case of Brasil. Economic and Social Study Series. São Paulo: FIPE/USP.

Arretche, M. (2000). Estado federativo e politicas sociais. Determinantes da descentralização. Rio de Janeiro: Renavan; São Paulo: Fapesp.

10 Dentro de un sinnúmero de temas que entraron en la agenda de la política urbana a partir de este proceso, destacamos la regularización del suelo integral de los asentamientos informales. 
Avelino Filho, G. (1994). Clientelismo e política no Brasil. Revistando velhos problemas. Novos Estudos CEBRAP, 38, 225-240.

Avritzer, L. (2003). Modelos de deliberação democrática: uma análise do orçamento participativo no Brasil. En S. Boaventura (Org.) (2003), Democratizar a democracia: os caminhos da democracia participativa. Colección Reinventar a emancipação social. Rio de Janeiro: Afrontamento.

Boaventura, S. (Org.) (2003). Democratizar a democracia: os caminhos da democracia participativa. Coleção Reinventar a emancipação social. Rio de Janeiro: Afrontamento.

BRASIL, Ministério das Cidades (2004). Plano diretor participativo. Guia para a elaboração pelos municípios e Cidadãos. Brasília: Ministério das Cidades/Confea.

BRASIL, Ministério das Cidades (2004). Política Nacional de Desenvolvimento Urbano; Participação e Controle Social; Planejamento Territorial Urbano e Política Fundiária; Habitação; Saneamento Ambiental; Mobilidade Urbana; Trânsito; Capacitação e Informação (8 volúmenes).

BRASIL, Ministério das Cidades, Secretaria Nacional de Programas Urbanos (2005). Planos diretores participativos. Brasília: Ministério das Cidades.

Bremaeker, F. (2006). Panorama da finanças municipais em 2005. IBAM, Série Estudos Especiais, 184.

Bremaeker, F. (2008). As finanças municipais em 2007. Estudo Técnico No 2. Transparência municipal.

Carvalho. J. (1997). Mandonismo, coronelismo, clientelismo. Uma discussão conceitual. Dados, Revista de Ciências Sociais, 40, 2.

Dagnino, E. \& Olvera, A. \& Panfichi, A. (Org.) (2006). A disputa pela construção democrática na América Latina. São Paulo: Paz e Terra.

Ferreira, J. (2007). O mito da cidade global. O papel da ideologia na produção do espaço urbano. São Paulo: Vozes/UNESP/ANPUR.

Gomes, C. (1998). A politica brasiliera em busca da modernidade. Na fronteira entre o público e o privado. En L. Schwarcz (Org.), Historia da vida privada no Brasil: contrastes da intimidade contemporânea (Vol. 4). São Paulo: Companhia das Letras.

Graham, R. (1990). Patronage and politics in nineteenth-century Brazil. Stanford: Stanford University Press.

IBGE, Instituto brasileiro de geografia e estatística (2006). Pesquisa de informaçóes básicas municipais. Rescatado de www.ibge.gov.br.

Lavalle, A.; Houtzager, P. \& Costello, G. (2006). Democracia, pluralização da representação e sociedade civil. Revista Lua Nova, 67, 49-103.

Limongi, F. \& Figueiredo, A. (2005). Processo orçamentário e comportamento legislativo: emendas individuais, apoio ao executivo e programas de governo. Dados, 48, 004, 737 776.

Maricato, E. (1996). Metrópole na periferia do capitalismo. São Paulo: Hucitec.

Maricato, E. (2006). Terra e habitação: elementos estratégicos da política nacional de desenvolvimento urbano. Série Estudos Sociais, IPEA.

Marques, E. (2003). Estado e empreiteiras II. Permerabilidade e políticas urbanas. Dados, Revista de Ciências. Sociais, 46, 1, 39-74.

Martins, C. (2003). Liberalismo: o direito e o avesso Dados, Revista de Ciências. Sociais, 46, 4, 619-660. 
Melo, M. \& Rezende, F. (2004). Descentralization and governance in Brazil. En J. Tulchin \& A. Selee (Eds.), Decetralization and democratic governance in Latin America (No 12). Woodrow Wilson International Center Reports on the Americas.

Milani, C. (2006). Les paradoxes du "principe participatif" dans la gestion public locale. En D. Eeuwen (2006), Le nouveau Brésil de Lula. France: Ed. De L'Aube.

Nunes, E. (1997). A gramática política do Brasil. Clientelismo e insulamento burocrático. Rio de Janeiro: Jorge Zahar.

Oliveira, F. (1988). A economia brasileira. Critica razão dualista. Petrópolis: Vozes.

Paoli, M. (1995). Movimentos sociais no Brasil. Em busca de um estatuto político. En M. Hellman (Org.), Movimentos sociais e democracia no Brasil. Natal: Marco Zero.

Pereira, C. \& Mueller, B. (2002). Comportamento estratégico em presidencialismo de coalizão. As relaçôes entre executivo e legislativo na elaboração do orçamento brasileiro. Dados, Revista de Ciências Sociais, 45, 2, 22, 265-301.

Pierson, P. (2000). Increasing returns, path dependence and the study of politics. The American Political Science Review, 94, 2.

Sader, E. (1988). Quando novos personagens entram em cena. São Paulo: Paz e Terra.

Santos Jr., O. \& Ribeiro, L. (2003). Democracia e segregação urbana. Reflexões sobre a relação entre cidade e cidadania na sociedade brasileira. Eure, 29, 88, 79-95.

Santos Jr., O. (2004). Reforma urbana e gestão democrática. Um ano de funcionamento do Conselho das Cidades. Relatório para FASE, mimeo.

Santos Jr., O. (2007). Cidade, cidadania e planejamento urbano. Desafios na perspectiva da reforma urbana. En S. Feldman \& A. Fernandes (Orgs.), O Urbano e o regional no Brasil contemporâneo: mutaçóes, tensóes, desafios. Salvador: EDUFBA.

Sennett, R. (1988). O declinio do homem público: as tiranias da intimidade. Sáo Paulo: Companhia das Letras.

Silva, P. (2003). Limites e obstáculos à reforma do Estado no Brasil. A experiência da previdência social na Nova República. Campinas: Instituto de Economia - IE; UNICAMP.

Sistema Integrado de Administração Financeira do Governo Federal, SIAFI (2007). Rescatado de http://www.stn.fazenda.gov.br/siafi/index.asp.

Smolka, M. (2003). Informalidad, pobreza urbana y precios de la tierra. Perpectivas urbanas. Land Lines, 1. Lincoln Institute of Land Policy.

Smolka, M. (2003). Regularização da ocupação do solo urbano. A solução que é parte do problema, o problema que é parte da solução. En P. Abramo (Org.), A cidade da informalidade. Os desafios das cidades latino-americanas. Rio de Janeiro: Sette Letras/ FAPERJ.

Souza, M. A. (1999). O II PND e a política urbana brasileira: uma contradição evidente. En C. Deak \& Schiffer, S. (Orgs.), O processo de urbanização no Brasil. São Paulo: EDUSP.

Souza, M. L. (2005). O desafio metropolitano. Um estudo sobre a problemática sócio-espacial nas metrópoles brasileiras. Rio de Janeiro: Bertrand Brasil.

Telles, V. (2007). Trajetórias urbanas. En E. Dagnino \& L. Tatagiba (Orgs.), Democracia, sociedade civil e participação. Chapecó: Editora Argos.

Wacquant, L. (2007). Parias urbanos. Marginalidad en la ciudad a comienzos del milenio. Buenos Aires: Manantial. 
